\title{
Modal Analysis of Lenses Used in Automotive Lighting Industry and Obtaining MAC Matrix
}

\author{
Erhan Ay ${ }^{a *}$, Barış Ediz ${ }^{b}$, Birhat Sönmezay ${ }^{c}$ Sevda Telli Çetin ${ }^{d}$ \\ ${ }_{a, b, c} R \& D$ Department/Magneti Marelli Mako Elektrik Sanayi ve Ticaret A.Ş., Turkey \\ ${ }^{d}$ Mechanical Engineering Department/Uludağ University, Turkey

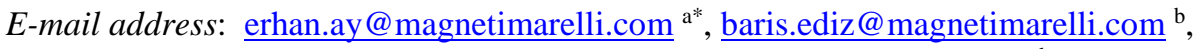 \\ birhat.sonmezay@magnetimarelli.com ${ }^{\mathrm{c}}$, sevda@uludag.edu.tr ${ }^{\mathrm{d}}$
}

ORCID numbers of authors:

0000-0001-9621-6030 $, 0000-0002-2704-7090^{b}, 0000-0002-8432-6192^{c}, 0000-0002-3281-9112^{d}$

Received date: 28.05 .2019

Accepted date: 01.07.2019

\begin{abstract}
In this study, 4 different pieces of automotive rear lamp lenses which are made of Polymethylmethacrylate (PMMA) and have different geometries have been inspected. Free-free natural frequencies and mode shapes of lenses have been estimated by the help of ANSYS WB ${ }^{\circledR}$ Finite Element Analysis (FEA) software. Meanwhile, by the help of Experimental Modal Analysis (EMA) methods; natural frequencies, damping ratios and mode shapes of the lenses have been determined. Finally, mode shapes calculated by FE and measured by EMA were compared and Modal Assurance Criteria matrix (MAC) was determined. After experimental modal tests, FRF's were calculated by DEWESoft ${ }^{\circledR} X 3$ software then natural frequencies, damping ratios and mode shapes were calculated by the use of ME'scope ${ }^{\circledR}$ VESVT-570 Visual Modal software. In addition, MAC was calculated by the help of MEScope ${ }^{\circledR}$ software. The main reason for the use of such experimental methods was to understand if the assumptions made before theoretical analysis were satisfied in reality or not.
\end{abstract}

Keywords: Auotomotive Lighting, Polymethylmethacrylate, Finite Element Modal Analysis, Experimental Modal Analysis, Modal Assurance Criteria (MAC)

\section{Introduction}

The reaction of the structures used in engineering under the influence of static and dynamic forces is very important in the design phase of these structures. In order to investigate the reactions of the structures under the influence of dynamic forces, the free vibration characteristics must be determined in the first stage. Free vibration characteristics are the mode shapes of the structure, damping ratio and vibration frequencies. The comparison of the frequencies of the forces coming to the structure and the free vibration frequencies are important for the resonance event. In addition, it is very important to determine how the structure behaves under the influence of these forces in the investigation of the response of structures to dynamic forces. 
The machines manufactured today are exposed to very high vibration forces due to their high speed and elastic structure. The frequencies of these forces are especially worth knowing about the resonance vibrations. Because, if the frequency of one or more of the driving forces coincides with the natural frequencies of the system, resonance vibrations with a destructive effect occur. Therefore, vibration analysis should be done at the design phase in order to avoid resonance vibrations and unwanted dynamic conditions. A number of simple studies that will be done during the design phase can prevent the future large vibration problems [1].

Altunel (2009) in his study, structural finite element model updating of a utility helicopter fuselage was performed as a case study. Initially, experimental modal analyses were performed using modal shakers. Modal analysis of test results was carried out using LMS Test.lab ${ }^{\circledR}$ software. At the same time, finite element analysis of the helicopter fuselage was performed by MSC.Patran \& Nastran software. Initial updating was processed first for the whole helicopter fuselage then, tail of the helicopter was tried to be updated.

Furthermore, a new method was proposed for the optimum node removal location for getting better Modal Assurance Criterion (MAC) matrix. This routine was tried on the helicopter case study and it showed better performance than the Coordinate Modal Assurance Criterion (coMAC) that is often used in such analyses [2].

Gündoğan (2012) in her study, system identification of a model steel bridge has been performed and calibrated finite element model of the bridge is obtained. Although there are many different system identification types, in this study only NExT-ERA and ERA methods are used. Methods are programmed using Matlab. As a result of this study, modal parameters (mode shapes, natural frequencies, and damping ratios) of the structure has been estimated. On the other hand, modal assurance criteria (MAC) is calculated to mode shapes between NExT-ERA, ERA results and SAP2000 analysis results. It has been shown that mode shapes are in good agreement with each other. Natural frequencies, obtained from NExT-ERA and ERA, are also in good agreement [3].

Ay (2019), in his study; first of all, finite element undamped modal analysis was performed on one of the automotive rear lamp lenses and were obtained natural frequencies and mode shapes. Then, Frequency Response Functions (FRF) of an automotive rear lamp lens, made of polycarbonate (PC) material, were obtained by using Impact Hammer Test Methods. At the same time; dynamic characteristics of the structure, natural frequencies, damping ratios and mode shapes were obtained. Damping ratios were calculated from the FRF's by using the Half Power Method. Finite Element Analysis (FEA) results and test results were compared and the best test method was determined [4].

Ay (2019), in his study, the weight of the modal accelerometer used in the Roving Hammer Impact Test Method was added in the finite element analysis (FEA) and the undamped modal analysis of the automotive rear lamp lenses were performed. Also, calculated new Elastic Modulus for Polymethyl-methacrylate (PMMA) material with using natural frequency formula and this value was used in the ANSYS WB® program and the undamped modal analysis was repeated. After that, frequency response functions (FRFs) of an automotive rear lamp lens were obtained by using Roving Hammer Impact Test Method. At the same time; dynamic characteristics of the structure, natural frequencies, damping ratios and mode shapes were obtained. Damping ratios were calculated from the FRF's by using the Half Power Method. Finally, experimental modal analysis (EMA) and FEA results were compared [5]. 
The main aim of this study comparison of FEA results with the results of the Roving Hammer test for automotive rear lamp lenses made of PMMA material. EMA measurements were performed on the models. In order to make a comparison of experimental and analysis results, the analyses of the measured models with finite element method were also performed. In the EMA measurements, impact hammer and modal accelerometers were used. With the impact hammer at the points determined on the structures, the drive operation was carried out and the force applied to the structure with the force gauge at the end of the impact hammer was measured. Due to the applied force, the vibration in the structure was measured by the accelerometers placed at the determined points. The measured signals were processed in the DEWESoft ${ }^{\circledR}$ Sirius HD 16x STGS model data collection system to obtain FRF. FRF's were pre-controlled and natural frequencies were determined and the damping ratios corresponding to these natural frequencies were calculated by using the half power method.

Natural frequencies and mode shapes obtained by experiments and analysis were compared and Modal Assurance Criteria (MAC) was obtained. Then, the results obtained during the experiments and the results obtained from the comparison of experimental and theoretical results are presented.

\section{Material and Method}

\subsection{Modal assurance criteria (MAC)}

The MAC is used to determine the similarity of two mode shapes:

- If the mode shapes are identical (i.e., all points move the same) the MAC will have a value of one or $100 \%$.

- If the mode shapes are very different, the MAC value will be close to zero.

If a mode shape was compared to itself, the MAC value should be one or $100 \%$.

For modes with different shapes, the MAC is less than 1 . Shapes that are very different will have a value close to zero. Mode shapes that are used in the comparison can originate from a Finite Element Analysis (FEA) or from an Experimental Modal Analysis (EMA). In a typical MAC analysis, one might make a 'MAC Matrix'. A 'MAC Matrix' is a series of bar graphs of MAC values, that each range from 0 to $100 \%$ as shown in Fig. 1.

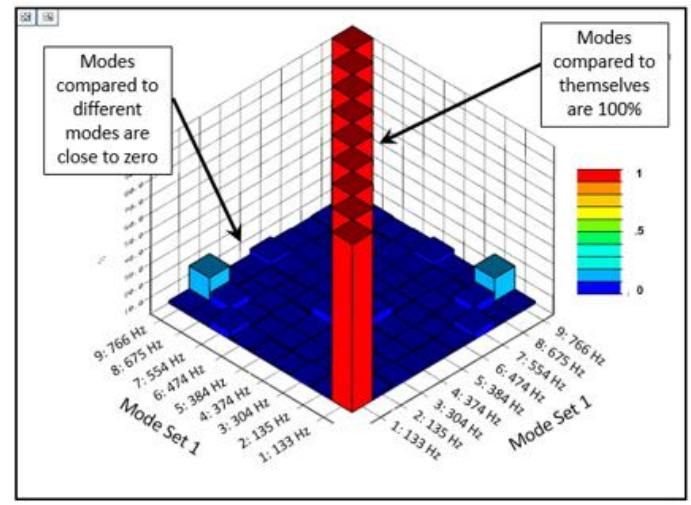

Fig. 1. MAC matrix comparing a set of 9 modes 
In Fig. 1, the first mode shape at $133 \mathrm{~Hz}$ is identical to itself, hence a single red bar of a value of 1 . Along the diagonal, every mode is identical to itself, 1 to $1(133 \mathrm{~Hz}), 2$ to $2(135 \mathrm{~Hz}), 3$ to $3(304 \mathrm{~Hz})$, etc.

Off of the diagonal, the MAC values are very low. Ideally, each mode should be uniquely observed and have a different shape than the other modes. This is the case for this mode set. The highest off diagonal mode pair is mode 2 compared to mode 9 (and vice versa 9 to 2) with a MAC value of $20 \%$. All the other off-diagonal mode pairs are below $20 \%$ [6].

\subsection{Modal assurance criterion equation}

The MAC value between two modes is essentially the normalized dot product of the complex modal vector at each common nodes (i.e., points), as shown in Eq. (1). It can also be thought of as the square of correlation between two modal vectors $\Phi \mathrm{r}$ and $\Phi$ s.

$$
\operatorname{MAC}\left(\left\{\Phi_{r}\right\},\left\{\Phi_{s}\right\}\right)=\frac{\left|\{\Phi\}_{r}^{* t}\{\Phi\}_{s}\right|^{2}}{\left(\left|\{\Phi\}_{r}^{* t}\{\Phi\}_{r}\right|\right)\left(\left|\{\Phi\}_{s}^{* t}\{\Phi\}_{s}\right|\right)}
$$

where * and t represents the complex conjugate and transpose of the vector respectively. MAC value can have values only between 0 and 1 . The value of 0 means that two vectors are orthogonal and there is no correlation between them. If the MAC value is 1, it means that vectors are fully correlated and equal to each other. The value below 0.3 are poorly correlated whereas above 0.8 are well correlated. Between these values, model can be updated to get MAC values above 0.8 [2].

A MAC analysis can be used in several different ways [7]:

- FEA - Test comparison: A MAC can be used to compare modes from an experimental modal analysis test to a FEA and an object. It will indicate if the same mode shapes are found in both the test and FEA analysis.

- FEA - FEA comparison: Several assumptions can be made in the creation of a FEA analysis: Young's Modulus, boundary conditions, and mass density values to name a few. A MAC analysis can determine the degree to which these assumptions affect the resulting mode shapes.

- Test - Test comparison: A MAC analysis can flag potential issues with the modal analysis results. Usually MAC will identify modes and areas that could benefit from acquiring more data points on the structure.

\subsection{FEA of automotive rear lamp lenses}

FEA was performed on automotive rear lamp lenses with 4 different geometries under free-free boundary conditions. For all lenses the first 3 flexible body mode shapes were investigated. In Fig. 2, Fig. 3 and Fig. 4, first, second and third flexible body mode shape are illustrated for the first sample respectively. 


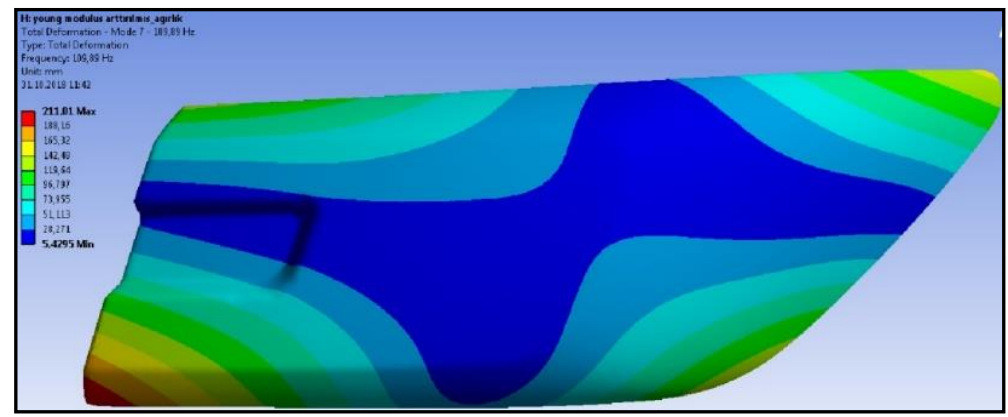

Fig. 2. First mode shape $(109.89 \mathrm{~Hz})$ for sample 1

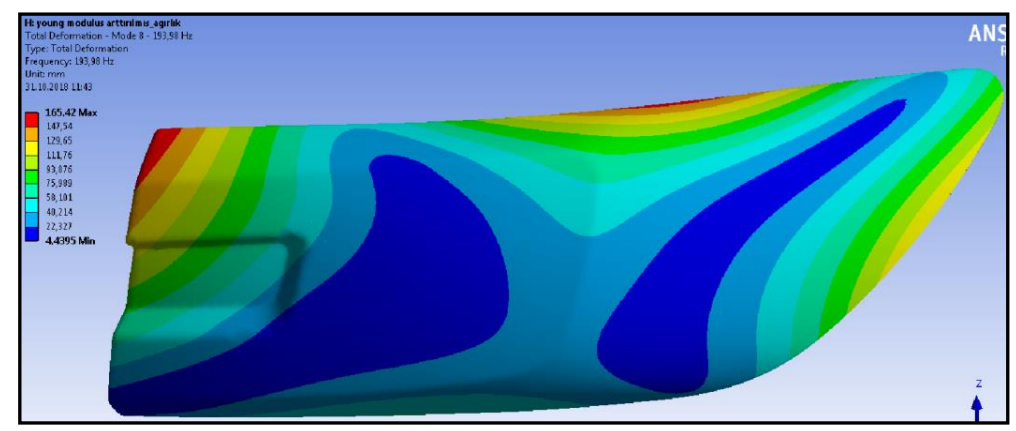

Fig. 3. Second mode shape $(193.98 \mathrm{~Hz})$ for sample 1

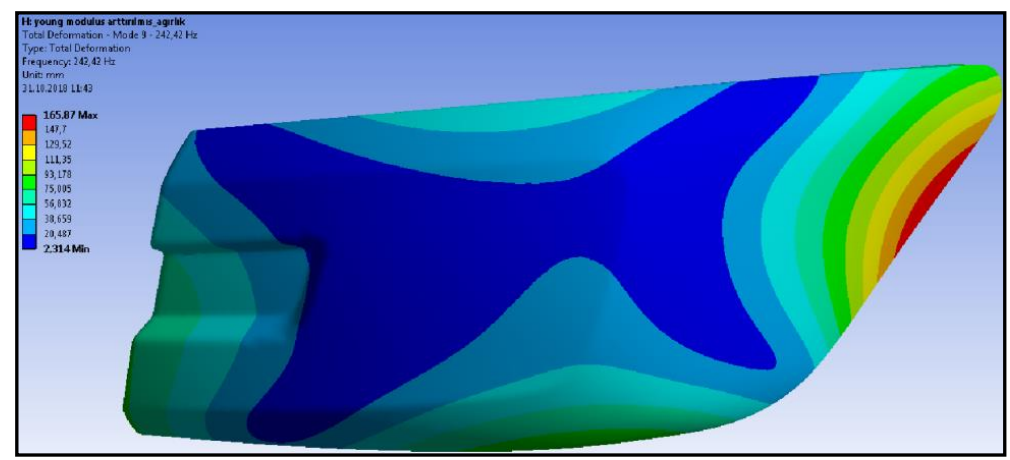

Fig. 4. Third mode shape $(242.42 \mathrm{~Hz})$ for sample 1

In Fig. 5, Fig. 6 and Fig. 7, first, second and third flexible body mode shape are illustrated for the second sample respectively. 


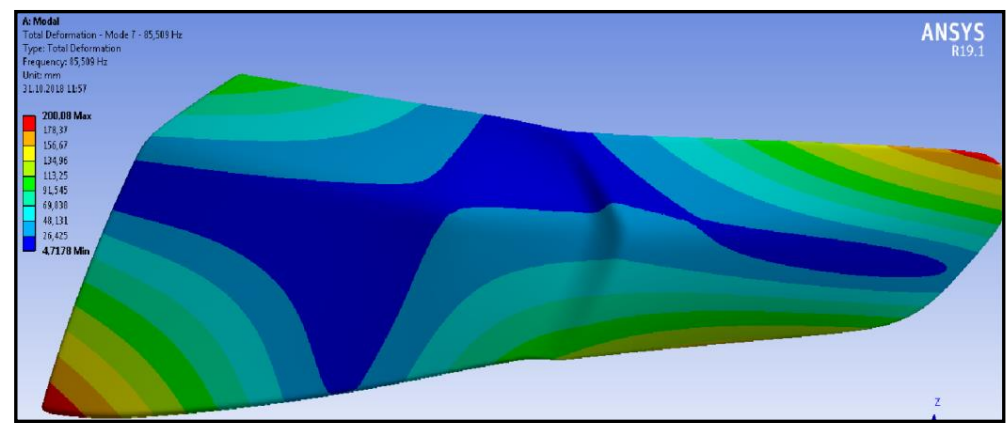

Fig. 5. First mode shape $(85.509 \mathrm{~Hz})$ for sample 2

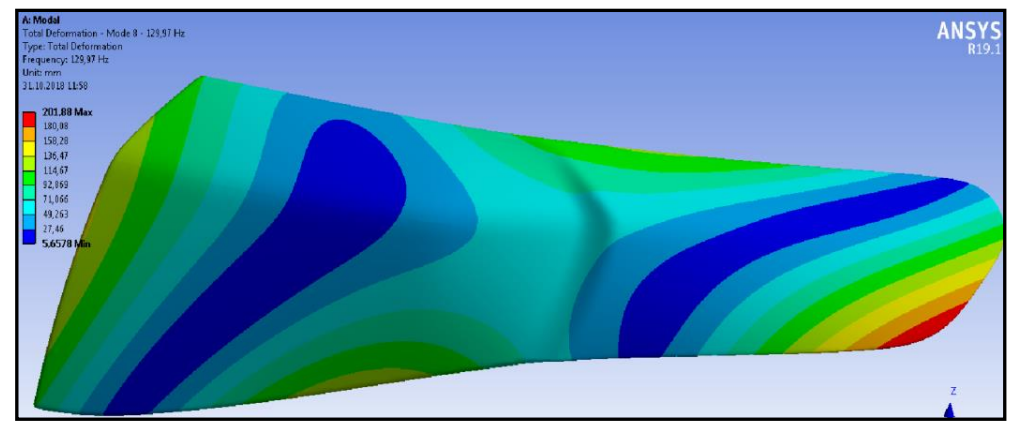

Fig. 6. Second mode shape $(129.97 \mathrm{~Hz})$ for sample 2

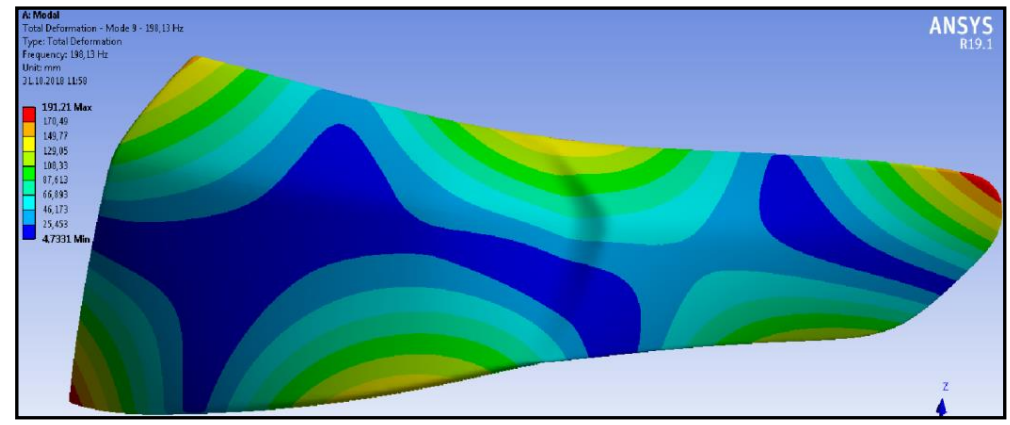

Fig. 7. Third mode shape $(198.13 \mathrm{~Hz})$ for sample 2

In Fig. 8, Fig. 9 and Fig. 10, first, second and third flexible body mode shape are illustrated for the third sample respectively. 


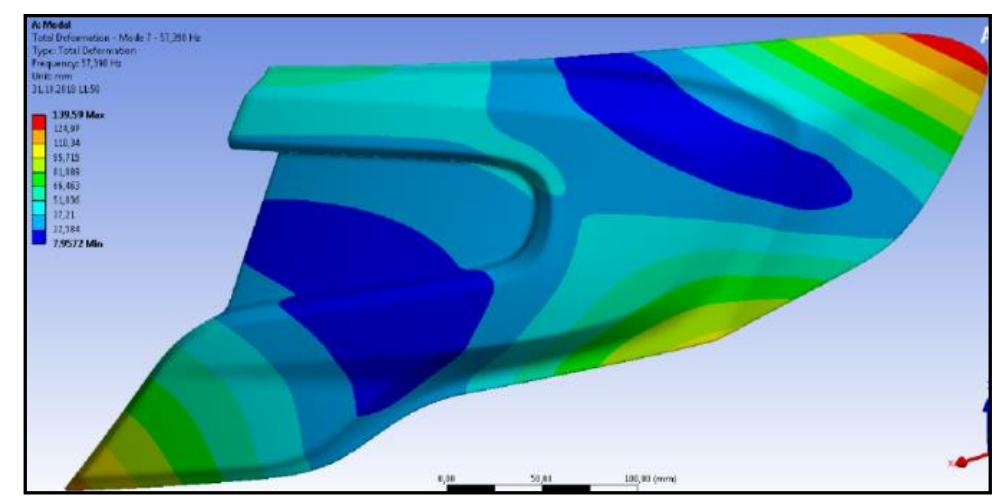

Fig. 8. First mode shape $(57.398 \mathrm{~Hz})$ for sample 3

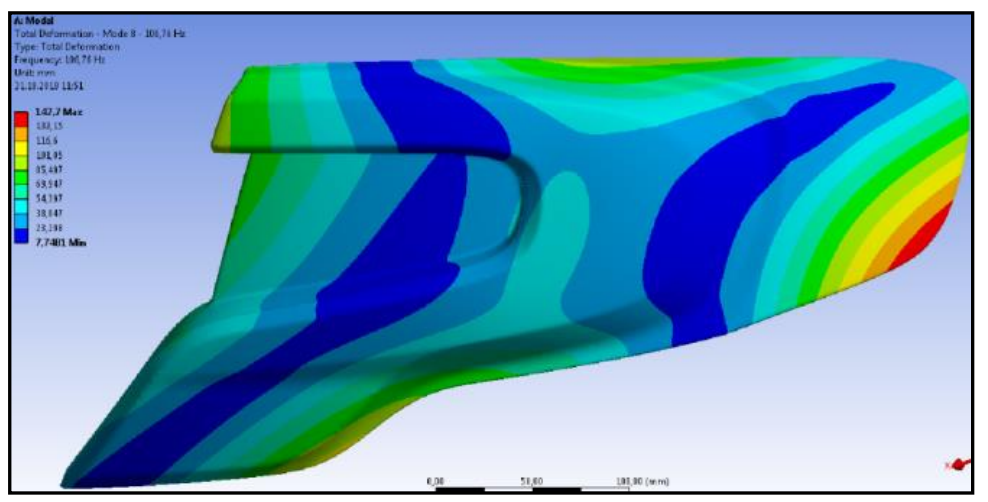

Fig. 9. Second mode shape $(106.76 \mathrm{~Hz})$ for sample 3

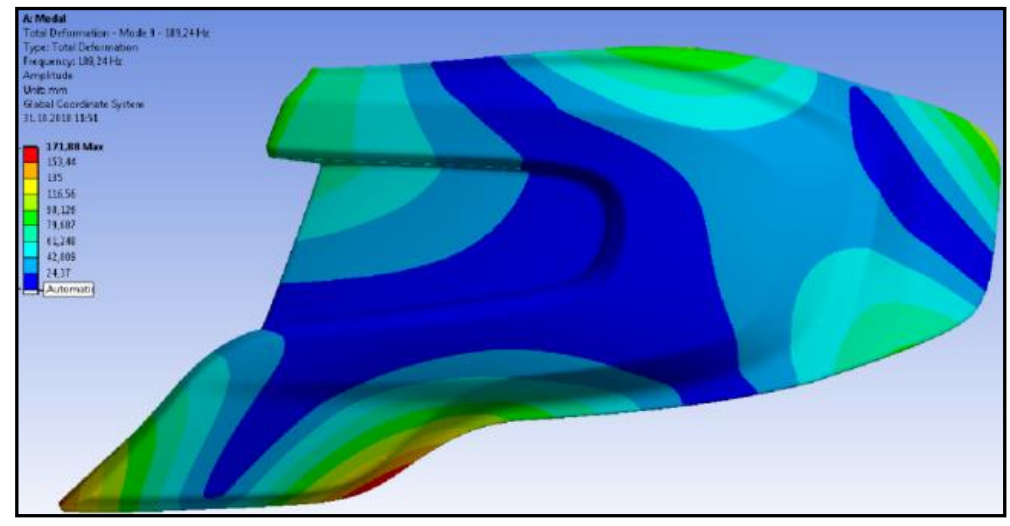

Fig. 10. Third mode shape (189.24 Hz) for sample 3

In Fig. 11, Fig. 12 and Fig. 13, first, second and third flexible body mode shape are illustrated for the fourth sample respectively. 


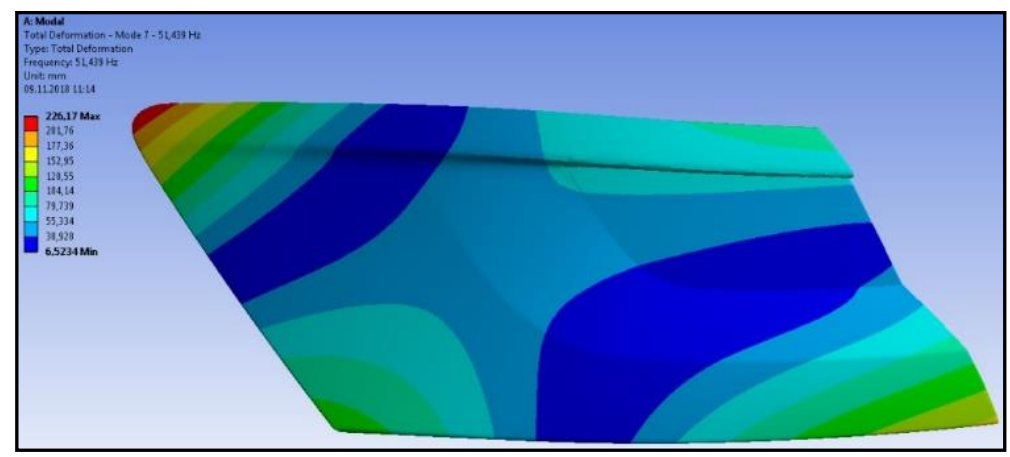

Fig. 11. First mode shape $(51.489 \mathrm{~Hz})$ for sample 4

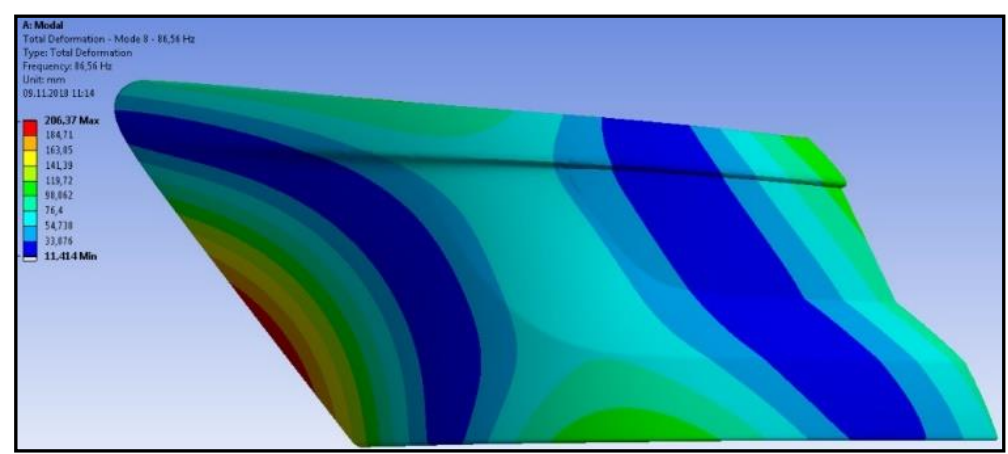

Fig. 12. Second mode shape $(86.56 \mathrm{~Hz})$ for sample 4

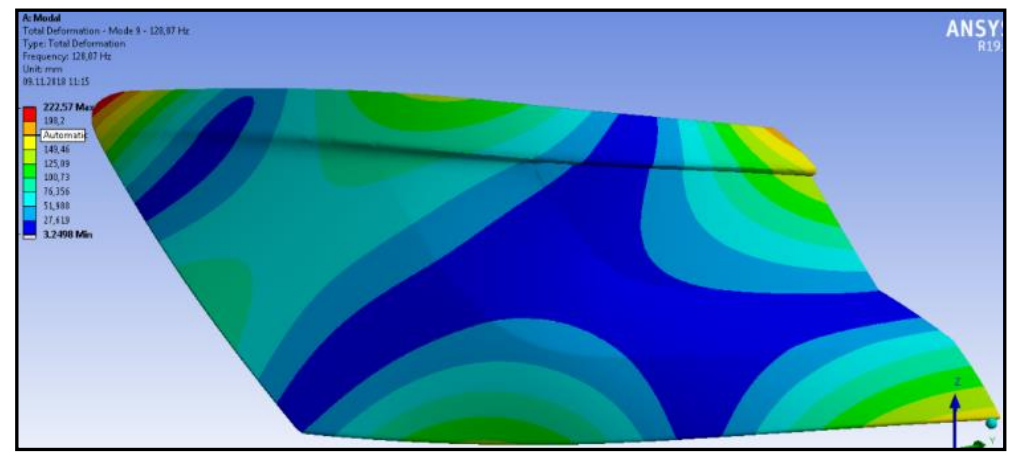

Fig. 13. Third mode shape $(128.87 \mathrm{~Hz})$ for sample 4

\subsection{EMA of automotive rear lamp lenses}

After FEA, EMA was performed on automotive rear lamp lenses with 4 different geometries. The lenses marked on the response and excitation points and was used impact hammer for test. Furthermore, the lenses were suspended from a single point to the testing apparatus using a single elastic rope to capture the condition closest to the free-free boundary conditions. For all lenses the first 3 flexible body mode shapes were investigated and the EMA natural frequency results were compared with the FEA natural frequency results. In Table 1, EMA natural frequency and FEA natural frequency results are illustrated for the first sample. 
Table 1. FEA and EMA natural frequency results for sample 1

\begin{tabular}{cccc}
\hline & FEA & EMA & (\%) \\
\hline 1.Mod & 109.89 & 110.871 & 0.884 \\
\hline 2.Mod & 193.98 & 201.230 & 3.602 \\
\hline 3.Mod & 242.42 & 393.477 & 38.390 \\
\hline \hline
\end{tabular}

In Table 2, EMA natural frequency and FEA natural frequency results are illustrated for the second sample.

Table 2. FEA and EMA natural frequency results for sample 2

\begin{tabular}{cccc}
\hline & FEA & EMA & $(\boldsymbol{\%})$ \\
\hline 1.Mod & 85.509 & 79.780 & 6.699 \\
\hline 2.Mod & 129.97 & 129.474 & 0.381 \\
\hline 3.Mod & 198.13 & 189.871 & 4.168 \\
\hline \hline
\end{tabular}

In Table 3, EMA natural frequency and FEA natural frequency results are illustrated for the third sample.

Table 3. FEA and EMA natural frequency results for sample 3

\begin{tabular}{cccc}
\hline & FEA & EMA & (\%) \\
\hline 1.Mod & 57.398 & 56.682 & 1.247 \\
\hline 2.Mod & 106.76 & 102.437 & 4.049 \\
\hline 3.Mod & 189.24 & 189.595 & 0.187 \\
\hline \hline
\end{tabular}

In Table 4, EMA natural frequency and FEA natural frequency results are illustrated for the fourth sample.

Table 4 FEA and EMA natural frequency results for sample 4

\begin{tabular}{cccc}
\hline & FEA & EMA & $(\boldsymbol{\%})$ \\
\hline 1.Mod & 51.489 & 53.884 & 4.444 \\
\hline 2.Mod & 86.56 & 88.138 & 1.790 \\
\hline 3.Mod & 128.87 & 135.835 & 5.127 \\
\hline \hline
\end{tabular}

\subsection{MAC calculation with using MEScope ${ }^{\circledR}$ software}

MEScope ${ }^{\circledR}$ software is used to calculate the MAC. Mesh structure was imported to MEScope ${ }^{\circledR}$ software which including the points where acceleration measurements were made in EMA and FRFs measured at these points were taken. The FRFs were matched with these points. The curve is obtained for each FRF and the mode shapes are acquired. 
Then the mesh structure and mode shapes used in the FEA model were imported into this software. These points are matched with the mode shapes. As a result of both EMA and FEA obtained mode shapes are examined.

Then, the points in the finite element mesh structure and the closest points in the mesh structure used in the EMA were matched.

After matching, mode shapes obtained by EMA and mode shapes obtained by FEA were compared using this program and MAC was calculated.

Thus, a validation was made between the FEA and the EMA.

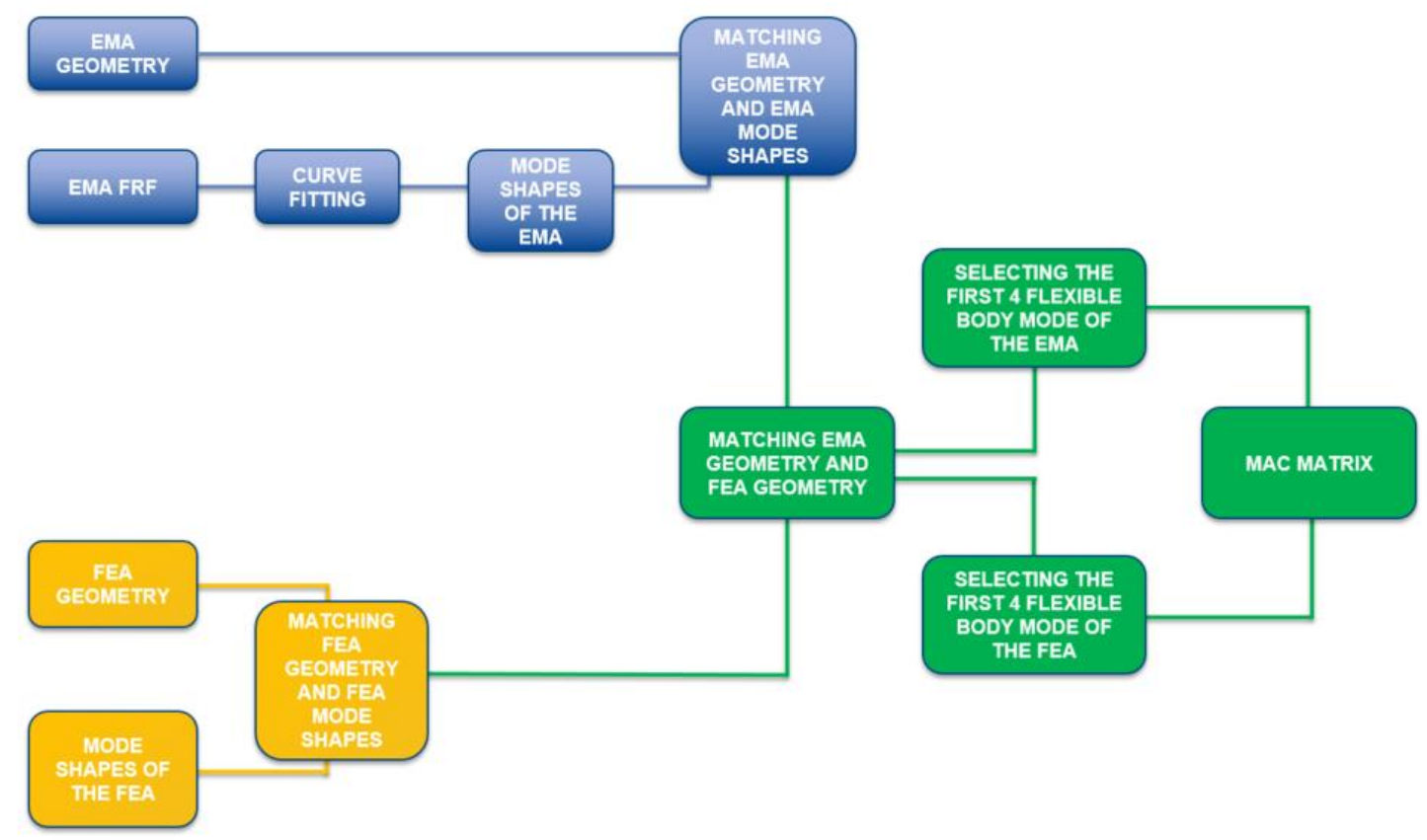

Fig. 14 MEScope ${ }^{\circledR}$ flow chart

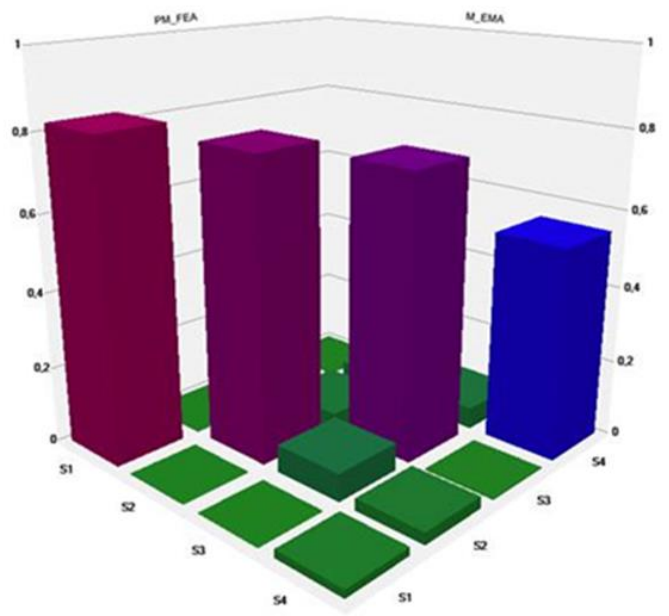

Fig. 15 MAC matrix for sample 1 


\begin{tabular}{|c|c|c|c|c|c|c|c|c|}
\hline & & & & & Shape 1 & Shape 2 & Shape 3 & Shape 4 \\
\hline & Label & \multicolumn{3}{|c|}{ PM_FEA } & & & & \\
\hline & \multirow{3}{*}{ M_EMA } & \multirow[t]{3}{*}{ Frequency(or Time) } & & & 112 & 201 & 386 & 508 \\
\hline & & & Damping & & 0 & 0 & 0 & 0 \\
\hline & & & & Damping $(\%)$ & 0 & 0 & 0 & 0 \\
\hline Shape 1 & Global-Poly & 114 & 3.13 & 2.74 & 0.822 & 0.00164 & 0,0481 & 0.00258 \\
\hline Shape 2 & Global-Poly & 205 & 6.9 & 3.36 & 0,00142 & 0.777 & 0.0456 & 0.0521 \\
\hline Shape 3 & Global-Poly & 407 & 9.59 & 2,36 & 4.87E-05 & 0.073 & 0.736 & 0.0567 \\
\hline Shape 4 & Global-Poly & 505 & 13.8 & 2.73 & 0.0212 & 0,0318 & 0,00295 & 0.548 \\
\hline
\end{tabular}

Fig. 16 MAC table for sample 1

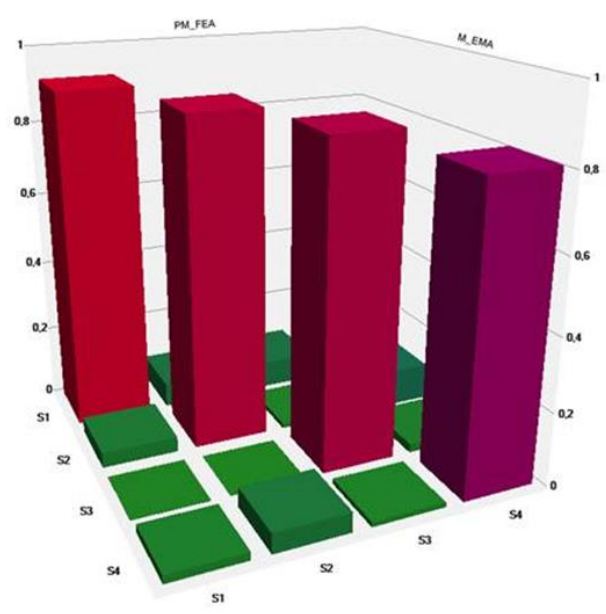

Fig. 17 MAC matrix for sample 2

\begin{tabular}{|c|c|c|c|c|c|c|c|c|}
\hline & & & & & Shape 1 & Shape 2 & Shape 3 & Shape 4 \\
\hline & \multirow[t]{2}{*}{ Label } & \multicolumn{3}{|c|}{ PM_FEA } & & & & \\
\hline & & \multirow[t]{3}{*}{ Frequency(or Time) } & & & 85.5 & 130 & 198 & 264 \\
\hline & M_EMA & & Damping & & 0 & 0 & 0 & 0 \\
\hline & & & & Damping $(\%)$ & 0 & 0 & 0 & 0 \\
\hline Shape 1 & Global-Poly & 81.1 & 3.53 & 4,35 & 0,916 & 0,0673 & 0,0747 & 0,00618 \\
\hline Shape 2 & Global-Poly & 128 & 4.31 & 3,36 & 0,0419 & 0,887 & 0,0144 & 0,102 \\
\hline Shape 3 & Global-Poly & 191 & 6.67 & 3,49 & 0,00237 & 0,00034 & 0,866 & 0,0246 \\
\hline Shape 4 & Global-Poly & 258 & 7.57 & 2,93 & 0.0226 & 0.0546 & 0.0136 & 0.808 \\
\hline
\end{tabular}

Fig. 18 MAC table for sample 2

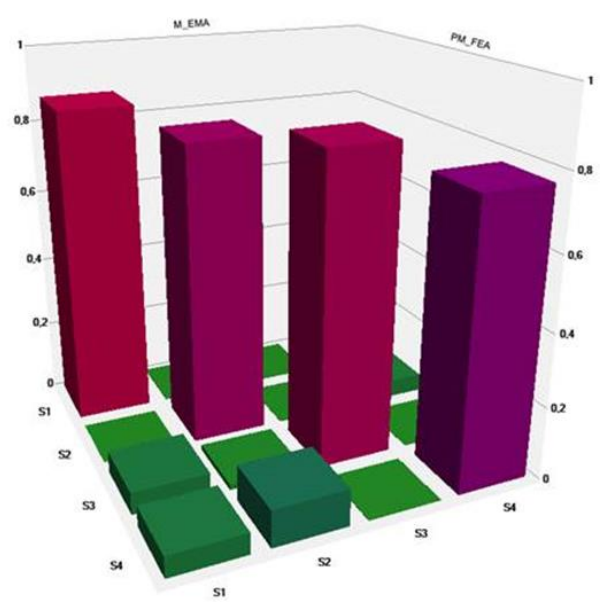

Fig. 19 MAC matrix for sample 3 


\begin{tabular}{|c|c|c|c|c|c|c|c|c|}
\hline & & & & & Shape 1 & Shape 2 & Shape 3 & Shape 4 \\
\hline & Label & & M_EMA & & Global-Poly & Global-Poly & Global-Poly & Global-Poly \\
\hline & & Frequency(or Time) & & & 56.3 & 102 & 190 & 221 \\
\hline & PM_FEA & & Damping & & 1.73 & 3.09 & 5.05 & 6.21 \\
\hline & & & & Damping $(\%)$ & 3.08 & 3.03 & 2,66 & 2,82 \\
\hline Shape 1 & & 57.4 & 0 & 0 & 0.867 & 0.00223 & 0.000353 & 0.00496 \\
\hline Shape 2 & & 107 & 0 & 0 & $9.26 \mathrm{E}-05$ & 0.816 & 0,00119 & 0.0494 \\
\hline Shape 3 & & 189 & 0 & 0 & 0.0618 & 0.0157 & 0.839 & 0.000361 \\
\hline Shape 4 & & 226 & 0 & 0 & 0.0584 & 0.101 & 0,00179 & 0.77 \\
\hline
\end{tabular}

Fig. 20 MAC table for sample 3

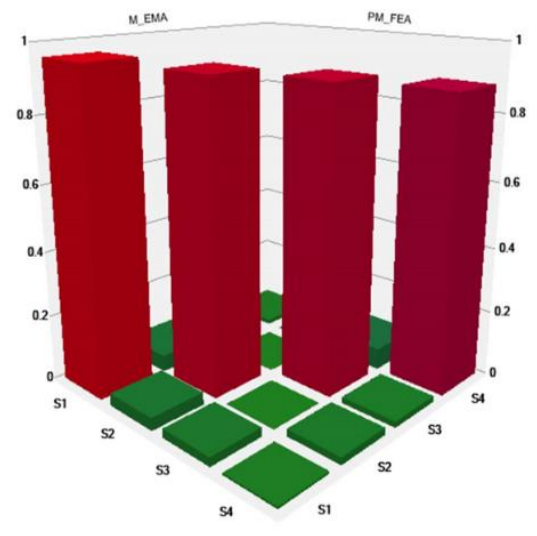

Fig. 21 MAC matrix for sample 4

\begin{tabular}{|c|c|c|c|c|c|c|c|c|}
\hline & & & & & Shape 1 & Shape 2 & Shape 3 & Shape 4 \\
\hline & \multicolumn{8}{|c|}{ PM_FEA_Shape_Table } \\
\hline & \multirow{3}{*}{ PM_EMA_Shape_Table } & Frequency(or Time) & & & 51.4 & 86.6 & 129 & 182 \\
\hline & & & Damping & & 0 & 0 & 0 & 0 \\
\hline & & & & Damping $(\%)$ & 0 & 0 & 0 & 0 \\
\hline Shape 1 & Global-Poly & 53.3 & 1.77 & 3,31 & 0.959 & 0.0386 & 0,0279 & 0.00669 \\
\hline Shape 2 & Global-Poly & 87.8 & 3.21 & 3.65 & 0.051 & 0.928 & 0.00161 & 0.0225 \\
\hline Shape 3 & Global-Poly & 133 & 3.79 & 2,85 & 0.0024 & 0.000795 & 0.908 & 0.0185 \\
\hline Shape 4 & Global-Poly & 184 & 7.7 & 4.19 & 0.0142 & 0.000481 & 0.0652 & 0.881 \\
\hline
\end{tabular}

Fig. 22 MAC table for sample 4

\section{Conclusions}

In this study, experimental modal analysis test was performed on lenses produced from PMMA material used in automotive lighting industry. Test results and finite element modal analysis results were compared and MAC matrix was calculated using MEScope ${ }^{\circledR}$ software.

As a result;

- When looking at the similarity status of the first 4 modes for sample $1 ; 0.822,0.777,0.736$, 0.548 
- When looking at the similarity status of the first 4 modes for sample $2 ; 0.916,0.887,0.866$, 0.808

- When looking at the similarity status of the first 4 modes for sample $3 ; 0.867,0.816,0.839$, 0.77

- When looking at the similarity status of the first 4 modes for sample $4 ; 0.959,0.928,0.908$, 0.881

it was found to be quite close to each other.

\section{Notations}

$\begin{array}{ll}\Phi_{r} & \text { EMA modal vector } \\ \Phi_{s} & \text { FEA modal vector }\end{array}$

\section{References}

[1] Selman Tümer, T., Uçak kanadında titreşim analizi (Y. Lisans Tezi), CBÜ, Makine Mühendisliği Anabilim Dalı, Manisa, 2016.

[2] Altunel F., Modal updating of a helicopter structure using a newly developed correlation improvement technique (Y. Lisans Tezi), ODTÜ, Makine Mühendisliği Anabilim Dalı, Ankara, 2009.

[3] Gündoğan, M., Çelik model köprünün yapı sağlı̆̆ının gözlenmesi (Y. Lisans Tezi), DEÜ, İnşaat Mühendisliği Anabilim Dalı, İzmir, 2012.

[4] Ay, E., Ediz, B., Çal, T., Telli Çetin, S., Modal analysis of automotive rear lamp lens produced from plastic material. International Journal of Automotive Science and Technology, (under review), 2019.

[5] Ay, E., Ediz, B., Çal, T., Telli Çetin, S. ,Calculation of the modulus of elasticity with using natural frequency formula and updated finite element analysis of automotive rear lamp lens. International Journal of Automotive Science and Technology, 3 (2): 27-31, 2019.

[6]Anonymous, Modal criterion assurance (MAC). https://community.plm.automation.siemens.com/t5/Testing-Knowledge-Base/ModalAssurance-Criterion-MAC/ta-p/368008,2016.

[7] Pastor, M., Binda, M., Harčarik, T. 2012. Modal assurance criterion. Science Direct. 